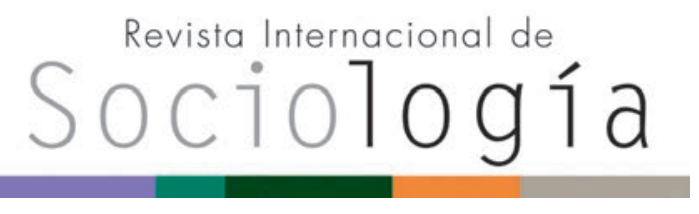

Revista Internacional de Sociología RIS

vol. 77 (1), e118, enero-marzo, 2019, ISSN-L:0034-9712 https://doi.org/10.3989/ris.2019.77.1.17.102

\title{
LA PESADA MOCHILA DEL ORIGEN DE CLASE. Escolaridad y movilidad intergeneracional de clase en Argentina, Chile y México
}

\author{
PatRICIO Solís \\ El Colegio de México \\ psolis@colmex.mx \\ https://orcid.org/0000-0002-9470-8362 \\ Pablo Dalle \\ CONICET, Instituto Gino Germani-UBA \\ pablodalle80@hotmail.com \\ https://orcid.org/0000-0002-4367-8562
}

Cómo citar este artículo / Citation: Solís, P. y P. Dalle. 2019. "La pesada mochila del origen de clase. Escolaridad y movilidad intergeneracional de clase en Argentina, Chile y México". Revista Internacional de Sociología 77(1):e118. https://doi.org/10.3989/ ris.2019.77.1.17.102

\begin{abstract}
Resumen
Analizamos el papel de la escolaridad en la movilidad intergeneracional de clase en Argentina, Chile y México. Para entender el papel de la escolaridad es importante identificar sus efectos como mediadora, ecualizadora y atenuante. Especificamos conceptual y metodológicamente estos efectos y generamos indicadores empíricos para ellos, usando datos de encuestas nacionales de movilidad social. Nuestros resultados indican que la escolaridad es un fuerte mediador en los tres países. Sin embargo, su papel como ecualizador varía entre países y no existe de un papel significativo como atenuante de la asociación entre orígenes y destinos de clase. Por tanto, cualquier interpretación simplista del efecto de la escolaridad en la movilidad de clase en América Latina se confrontará con una realidad más compleja, en la que la escolaridad es claramente una variable interviniente importante, pero tiene una contribución limitada en la neutralización de los efectos de los orígenes en los destinos de clase.
\end{abstract}

\section{Palabras Clave}

América Latina; Desigualdad de oportunidades; Escolaridad; Movilidad social.

\section{THE HEAVY BACKPACK OF CLASS ORIGINS. Schooling and Intergenerational Class Mobility in Argentina, Chile and Mexico}

Copyright: () 2019 CSIC. Este es un artículo de acceso abierto distribuido bajo los términos de la licencia de uso y distribución Creative Commons Reconocimiento 4.0 Internacional (CC BY 4.0).

Recibido: 11/07/2017. Aceptado: 01/10/2018

\section{Abstract}

We analyze the role of schooling on intergenerational class mobility in Argentina, Chile, and Mexico. In order to understand the role of schooling it is important to identify its effects as mediator, equalizer and attenuator. We specify, both conceptually and methodologically, these effects and generate empirical indicators for them, using data from national mobility surveys. Our findings indicate that schooling is a powerful mediator in the three countries. However, there are variations between countries in the role of schooling as equalizer and there is no evidence of a significant role as attenuator of the association between class origins and destinations. This suggests that any simplistic interpretation of the effects of schooling on class mobility in Latin America is confronted by a more complex reality, in which schooling is surely an important intervening variable, but has a limited contribution in neutralizing the effects of class origins on class destinations.

\section{KEYWORDS}

Inequality of opportunity; Intergenerational social mobility; Latin America; Schooling. 


\section{INTRODUCCIÓN}

En América Latina ( $A L)$, la región más desigual del mundo, la expansión educativa es frecuentemente considerada como el principal medio para reducir la pobreza e incrementar la movilidad social. De acuerdo con esta interpretación, la expansión educativa contribuiría a incrementar el capital humano y, a través de ello, a romper con la reproducción intergeneracional de la desigualdad. ¿En qué medida esta interpretación se sostiene empíricamente?

La escolaridad en AL fue comparativamente baja en relación con su desarrollo socioeconómico desde la Segunda Guerra Mundial hasta fines del siglo XX. Se ha afirmado que la expansión lenta y desigual de la escolaridad, en comparación con otras regiones (en particular con los países asiáticos) tuvo consecuencias negativas en la distribución de ingresos y la persistencia de altas tasas de pobreza (Londoño 1996). Sin embargo, en décadas recientes el ritmo de incremento de la matrícula de los niveles secundario y superior, así como el de egresados universitarios, fue superior al de otras regiones (Bellei 2013). Este incremento parece haber tenido un efecto positivo en la reducción de la desigualdad de ingresos (López Calva y Lustig 2010), aunque la evidencia se basa en datos transversales, es decir, de momentos fijos en el tiempo, lo cual ofrece poca información sobre la desigualdad de oportunidades en perspectiva intergeneracional.

Para analizar la desigualdad de oportunidades es necesario pasar del examen de la desigualdad distributiva al de la transmisión intergeneracional de la desigualdad. Es este tipo de análisis el que realizamos en este estudio. Específicamente, nos enfocamos en la transmisión intergeneracional de las posiciones de clase, lo cual nos ubica en el campo de los estudios sociológicos de movilidad social, que ha adquirido creciente importancia en América Latina (Torche 2005; Solís y Boado 2016), y tiene como una de sus preguntas fundamentales cuál es el papel de la escolaridad en la asociación entre orígenes (padres) y destinos (hijos) de clase. Esta es la pregunta en la que se centra nuestro trabajo.

Para entender el papel de la escolaridad en la movilidad intergeneracional de clase es importante distinguir entre tres tipos de efectos: mediación, ecualización, y atenuación. Aunque estos efectos son comúnmente referidos en la bibliografía especializada, frecuentemente son confundidos entre sí. Se suele aceptar que la escolaridad es el principal mediador en la asociación entre orígenes y destinos de clase, pero esto no necesariamente implica que desempeñe un papel ecualizador, ni mucho menos que contribuya a atenuar la intensidad de la asociación entre orígenes y destinos. Dado que, en última instancia, el potencial de la escolaridad para actuar sobre la desigualdad de oportunidades depende de sus efectos como ecualizador o atenuante, creemos que es importante establecer una distinción analítica y empírica entre estos dos efectos y la mediación.

Nos concentramos en los casos de México, Argentina y Chile, países con datos relativamente recientes sobre la movilidad intergeneracional de clase. Utiizamos modelos de regresión logística y loglineales que permiten distinguir los tres efectos citados. Estos modelos también nos ayudan a utilizar una perspectiva de clases sociales, lo cual es una novedad frente a estudios previos que se han enfocado en medidas continuas de estatus ocupacional de las personas, como las sugeridas por el "modelo de logro de status" de Blau y Duncan (1967).

El artículo se organiza de la siguiente manera. Primero discutimos el papel de la escolaridad como mediador, ecualizador y atenuante a través de una breve revisión de los estudios sociológicos sobre estratificación y movilidad social. Esta sección concluye con la lista de principales interrogantes para este artículo. En la segunda sección describimos las fuentes de datos, la construcción de las variables de clase social y escolaridad y los modelos estadísticos. Luego presentamos cuatro secciones de análisis empírico. En la primera describimos los cambios en la escolaridad y la estructura de clases, lo cual permite obtener una primera lectura de las semejanzas y diferencias entre países en las variables clave de nuestro estudio. En las tres secciones siguientes discutimos los efectos de la escolaridad como mediadora, ecualizadora y atenuante en la movilidad intergeneracional de clase para cada país. Por último, en la sección final retomamos los principales resultados y discutimos sus implicaciones para entender la relación entre movilidad social y escolaridad en AL.

\section{LA ESCOLARIDAD EN LA MOVILIDAD INTERGE- NERACIONAL DE CLASE: ASPECTOS CONCEP- TUALES, Estado DE LA CUESTIÓN Y AVANCES en AmÉrica Latina}

En el presente artículo analizamos la movilidad social intergeneracional con un enfoque de clases sociales, definidas a través de la posición en el mercado de trabajo. La posición ocupacional tiene un papel primordial en la generación de ingresos y, por ello, constituye una fuente central de desigualdad de condiciones de vida, de oportunidades y de poder (Erikson y Goldthorpe 1992; Breen 2004). Si bien definimos la movilidad social en términos de posiciones de clase, al revisar los avances de investigación sobre el papel de la escolaridad en la movilidad social reseñaremos los aportes de estudios que miden los orígenes y destinos sociales a través de escalas de estatus ocupacional. Precisamente, uno de los desafíos del artículo es pasar del enfoque de logro de estatus al de desigualdad de oportunidades de clase. 
El análisis de la desigualdad de oportunidades de clase se realiza a través del examen del nivel de fluidez social o movilidad relativa. La fluidez social mide las chances relativas de alcanzar un determinado destino de clase frente a las de permanecer en la clase de origen. Si estas chances no dependiesen del origen de clase, estaríamos en presencia de una sociedad con plena igualdad de oportunidades. Constituye una pauta empírica que la total independencia de orígenes y destinos de clase no existe en ninguna sociedad, pero el grado de fluidez social (medido a través de la intensidad de la asociación relativa entre orígenes y destinos de clase) es utilizado como un indicador de igualdad de oportunidades: a menor asociación relativa entre orígenes y destinos de clase, mayor fluidez social, menor desigualdad de oportunidades y mayor apertura en la estructura de clases (Breen 2004: 4).

Los estudios pioneros de estratificación social en AL consideraban que la modernización promovería la expansión de oportunidades educativas y ocupacionales. El incremento de la escolaridad constituiría uno de los canales principales de movilidad ascendente, contribuiría a nivelar las desigualdades sociales de origen y a conectar a las personas con las oportunidades que abría la expansión económica. Germani (1963) mostró que, en la transición del modelo agroexportador a la sustitución de importaciones, la escolaridad incrementó su influencia en las probabilidades de ascenso social, pues esta transición implicó mayores requerimientos de credenciales educativas para ascender en el marco de una estructura de clases más consolidada.

Los estudios que buscaron identificar el efecto mediador de la escolaridad en la movilidad intergeneracional ocupacional en AL se apoyaron en el modelo de "logro de estatus" de Blau y Duncan (1967). En la Gráfica 1 presentamos una versión simplificada de este modelo que es útil para ordenar la discusión posterior. A diferencia de enfoques previos, basados en el análisis bivariado de la tabla de movilidad de clase, Blau y Duncan propusieron examinar el logro ocupacional (D) a través de la descomposición de los efectos de los orígenes sociales $(\mathrm{O})$ y la escolaridad $(E)$. Este enfoque permite evaluar la influencia de los orígenes sociales en el logro educativo ('OE'); cuáles son los "retornos" ocupacionales de la escolaridad ('ED'); y cuál es la magnitud del efecto directo de los orígenes sociales sobre el destino ocupacional ('OD'), independientemente de su asociación a través de la escolaridad. A partir del cálculo de estos efectos, puede cuantificarse el efecto indirecto de los orígenes sociales a través de la escolaridad (OE*ED), y hasta qué punto la escolaridad es un mediador de los efectos totales de los orígenes sociales ([OE* $\mathrm{ED}] /$ / ([OE* $\mathrm{ED}]+\mathrm{OD})$.

Los resultados de Blau y Duncan (1967) en Estados Unidos mostraron que el efecto directo de $\mathrm{O}$ sobre $D$ era cada vez menor (-OD), mientras que su influencia indirecta a través de $E$ era cada vez más robusta $\left(+\mathrm{OE}^{*} \mathrm{ED}\right)$. Es decir, el papel mediador de la escolaridad se hacía cada vez más importante. Más tarde, Featherman y Hauser (1978: 481) constataron dos tendencias complementarias que daban cuenta de un proceso de apertura social: a través de sucesivas cohortes, el logro educativo se distribuyó más equitativamente según orígenes sociales (-OE), se morigeraron los patrones históricos de desigualdad racial y se incrementaron los retornos favorables de la escolaridad (+ED). Todas estas pautas indicaban un efecto potenciador de la escolaridad en la movilidad social, que favorecía mecanismos universales de logro.

En AL varios estudios continuaron esta línea. La preocupación central en la región durante los años sesenta y setenta era en qué medida los procesos de industrialización y urbanización promovían oportunidades de ascenso social. Una pregunta clave era si la marginalidad social, ya advertida en las grandes ciudades latinoamericanas, era una cuestión cristalizada o transitoria, posible de ser revertida a partir del crecimiento económico, la expansión de ocu-

Gráfica 1.

Modelo de logro de estatus simplificado

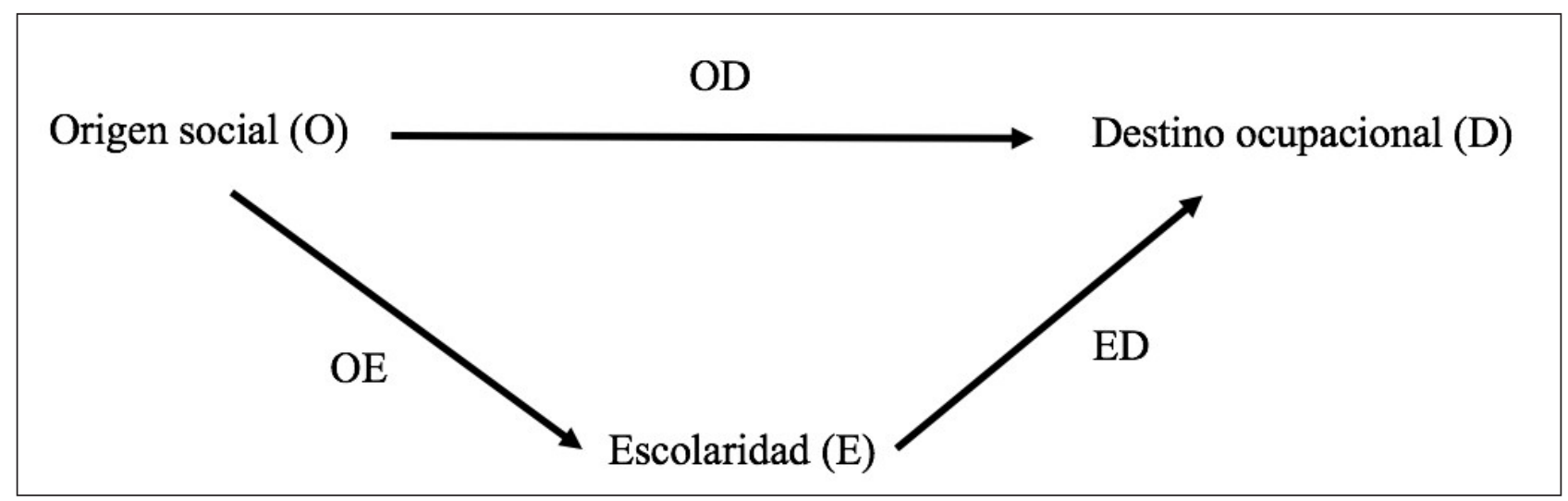


paciones fabriles y el acceso a mayores niveles de escolaridad de las generaciones jóvenes. Un trabajo clave en esta línea es el de Balán, Browning y Jelin (1977), quienes mostraron que en Monterrey, al igual que en Estados Unidos, O ejercía una débil influencia directa sobre D (-OD) y que su principal efecto era a través del logro educativo (+OE*ED), lo que nuevamente da cuenta de la importancia del papel mediador de la escolaridad. No obstante, O ejercía mayor efecto sobre $E$ en Monterrey que en Estados Unidos (+OE), y allí estaba la fuente de una mayor desigualdad de oportunidades.

Estudios más recientes han ahondado sobre la relación OED. En Argentina sobresalen los estudios de Jorrat $(2000,2016)$. Sus conclusiones concuerdan con los estudios citados: la escolaridad tiene mayor relevancia sobre el destino de las personas y es mediadora fundamental del efecto de los orígenes sociales. Comparando con los resultados de Blau y Duncan de Estados Unidos, la investigación de Jorrat (2000) en Buenos Aires dio cuenta de una sociedad algo más abierta: los efectos netos de las causas más cercanas (de tipo meritocrático) -de los años de escolaridad alcanzados y estatus de la primera ocupación-, arrojaron resultados más altos. Por otra parte, un estudio de Solís y Puga (2011) para México y Chile, basado en modelos similares a los desarrollados por Blau y Duncan, revela que en Chile existe una mayor asociación OD y que el papel mediador de E es menor al observado en México, diferencias atribuidas a la mayor desigualdad distributiva en Chile.

En paralelo, otros estudios en Argentina y México han intentado evaluar el papel mediador de la escolaridad a lo largo del tiempo, utilizando en lugar de escalas ocupacionales un enfoque de clases sociales (Solís 2007; Zenteno y Solís 2006; Dalle 2015; Alcoba 2014). Estos trabajos confirman que los efectos de los orígenes de clase sobre la clase de destino se canalizan, en gran medida, a través de su asociación con la desigualdad en logros educativos. No obstante, en todos ellos el efecto directo de la clase social de los padres se sostiene al controlar por por la escolaridad, particularmente en las cohortes jóvenes.

Como hemos corroborado a través de esta revisión, el papel mediador de la escolaridad en $\mathrm{AL}$ parece ser muy importante, e incluso quizás mayor que en países más industrializados. Esto no implica, sin embargo, que la escolaridad sea un ecualizador de las oportunidades de movilidad social. Más bien, nos indica que una fracción significativa de la asociación entre orígenes y destinos de clase pasa por la escolaridad.

La escolaridad juega un papel ecualizador en la medida en que ésta disminuye su vinculación con los orígenes sociales, al mismo tiempo que aumenta su importancia como determinante de los destinos de clase. Para ello, se tienen que presentar tres condi- ciones: primero, reducir la desigualdad de oportunidades educativas, es decir, minimizar la asociación OE; segundo, maximizar los retornos de clase de la escolaridad (ED); tercero, minimizar la relación directa entre orígenes y destinos de clase (OD). Así, los orígenes de clase tendrían efectos mínimos sobre los destinos de clase y primaría la asignación meritocrática de posiciones en función de talentos y esfuerzos personales, reflejados en el logro educativo.

Pocos estudios permiten evaluar empíricamente el papel ecualizador de la escolaridad en $A L$, y la evidencia no es muy alentadora. Algunos trabajos encuentran que los efectos directos OD son persistentes o incluso se han incrementado en el tiempo (Solís 2007; Zenteno y Solís 2006; Dalle 2015; Alcoba 2014, Cabrera 2016). Un trabajo relevante en esta línea es el de Torche y Costa-Ribeiro (2010) para Brasil, quienes analizan los cambios en el tiempo en los efectos de los orígenes sobre los destinos de clase, así como las asociaciones parciales OE y ED. Concluyen que si bien en Brasil se observa una tendencia hacia la reducción de la asociación entre orígenes y destinos de clase, lo que implicaría mayor fluidez social, este efecto no se explica por el papel ecualizador de la escolaridad, sino por la reducción de los retornos educativos (-ED), acompañada de un ligero incremento en la desigualdad de oportunidades educativas (+OE).

Además de ser mediador y ecualizador, la escolaridad puede ser un atenuante de la asociación entre orígenes y destinos de clase. Esto ocurre cuando a mayor escolaridad se debilita la asociación entre orígenes y destinos de clase. La noción de la escolaridad como atenuante se encuentra presente en los enfoques que privilegian su papel como vehículo de movilidad social y mecanismo igualador de oportunidades, como el de capital humano o la perspectiva liberal de la estratificación social. Estos enfoques sostienen que la escolaridad atenúa la relación entre orígenes y destinos de clase porque en los niveles más altos de escolaridad las credenciales educativas se convertirian en el factor más relevante para asignar las posiciones de clase a las personas, dejando sin importancia a sus antecedentes familiares (Breen y Jonsson 2005). Esta interpretación también se alinea con la tesis liberal, según la cual el proceso de modernización implica un mayor efecto de la escolaridad en la estratificación social, en detrimento de factores adscritos (Erikson y Goldthorpe 1992). Otro mecanismo que podría producir el efecto de atenuación es la selectividad social creciente de quienes avanzan en el sistema educativo (Mare 1980). Las personas de clases sociales de baja jerarquía que alcanzan altos niveles educativos presentan una selectividad social por un conjunto de características no observadas (habilidades, expectativas, motivación, apoyo familiar, etc.), que les permiten compensar sus desventajas socioeconómicas frente a quienes tienen orígenes 
más privilegiados. Por este efecto de selectividad, sería previsible que el efecto de los orígenes sociales sobre los resultados ocupacionales fuese menor en la medida en que se incrementa la escolaridad.

Paradójicamente, este efecto podría ser eclipsado por la expansión de la escolaridad y particularmente de la educación superior. La expansión de este nivel educativo entre las clases bajas implicaría una menor selectividad de los graduados universitarios provenientes de estas clases. Esto, aunado a las restricciones en la oferta laboral de alta calificación, reactivaría los criterios de selección laboral asociados a la clase social de origen entre los graduados universitarios (Vallet 2004; Solís 2007; Torche 2011).

Empíricamente, la atenuación implica una interacción estadística: la asociación OD se debilita con el incremento en la escolaridad. Existe evidencia en los países industrializados que respalda la hipótesis de atenuación. En su trabajo para Estados Unidos, Hout (1988) señaló que el incremento en la educación superior contribuye a la reducción de la desigualdad de oportunidades, pues la relación entre orígenes y destinos de clase era prácticamente nula entre los graduados universitarios. Más tarde, Torche reafirmó este efecto de atenuación de la educación superior, aunque con el caveat de que la asociación entre orígenes y destinos se incrementaba nuevamente entre quienes realizaban posgrados. En Europa, Vallet (2004) y Carabaña (2004) reportan un efecto de atenuación similar al señalado por Hout para el caso francés y español, respectivamente.

En AL, pocos estudios han sometido a prueba empírica esta hipótesis, con resultados que difieren de lo observado en los países industrializados. En Brasil, Torche y Costa-Ribeiro (2010) comparan la intensidad de la asociación OD (fluidez social) para distintos niveles de escolaridad. Su conclusión es que el incremento del nivel educativo no altera los niveles de fluidez. Para Argentina, Jorrat (2016) también muestra que la fluidez social no se incrementa a mayor escolaridad, e incluso identifica que el efecto podría ser el opuesto, es decir, que, a mayor nivel de escolaridad, la asociación entre orígenes y destinos de clase crece.

Como hemos visto, la escolaridad puede tener efectos de mediación, ecualización o atenuación de la asociación entre orígenes y destinos de clase. En este artículo buscamos identificar, en una perspectiva comparativa, cada uno de estos efectos. Por tanto, las preguntas que guían nuestro análisis empírico son:

a) ¿En qué medida la escolaridad es un mediador de la asociación entre orígenes y destinos de clase en cada país?

b) ¿En qué medida, independientemente de este papel mediador, se cumple en cada país la expectativa de que la escolaridad sea un ecualizador de oportunidades? En otras palabras, ¿cuál es el peso de la desigualdad de oportunidades educati- vas y los retornos ocupacionales de la escolaridad en cada país? ¿En qué países se logra que la escolaridad juegue un mayor papel ecualizador?

c) Adicionalmente a su papel como mediador y ecualizador, ¿es la escolaridad un atenuante de la asociación entre orígenes y destinos de clase? ¿Se incrementa la fluidez social entre quienes logran mayores niveles de escolaridad?

d) ¿Existen diferencias sustantivas por sexo en estos tres efectos?

\section{Datos, VARIABles Y MOdelos}

Utilizamos encuestas probabilísticas sobre movilidad intergeneracional de clase de cobertura nacional para Argentina, Chile y México. La referencia temporal de las encuestas es similar: corresponden a fines de la primera e inicios de la segunda década del siglo XXI. La encuesta de México fue relevada en 2011 por el Centro de Estudios Espinosa Yglesias. La de Chile en 2009, en el marco del proyecto CONICyT Anillo SOC12 que integraron varias instituciones: Universidad de Chile, Universidad de Santiago, Universidad Diego Portales y Centro de Estudios de la Mujer. En el caso de Argentina, con el objetivo de incrementar el tamaño de la muestra, hemos integrado dos encuestas con muestras independientes correspondientes a 2007-08 y 2009-10, relevadas por el Centro de Estudios de Opinión Pública de la Universidad de Buenos Aires.

Las encuestas cuentan con información sobre la ocupación principal de la persona entrevistada y la de su padre cuando el encuestado o la encuestada tenía 15 años. Tanto para orígenes como para destinos, incluyen una batería de indicadores de ocupación: la ocupación clasificada con la Clasificación Internacional Uniforme de Ocupaciones (CIUO) de 1988 de la Organización Internacional del Trabajo (OIT), la posición ocupacional (patrón, por cuenta propia o asalariado), el tamaño del establecimiento y la condición de supervisión ${ }^{1}$. El universo de análisis corresponde a la población de ambos sexos de 25 a 64 años con ocupación al momento de la encuesta. El tamaño de la muestra es de 5,671, 2,682 y 2,162 casos para México, Argentina y Chile, respectivamente.

Nos enfocamos en la relación entre las tres variables que integran el triángulo OED. Nuestro interés es identificar la magnitud de las asociaciones estadísticas entre estas tres variables a escala macrosocial y, a partir de ahí, derivar conclusiones sobre los efectos de mediación, ecualización y atenuación de la escolaridad entre la clase social de origen y de destino. Por ello, tal como como lo hacen muchos estudios de movilidad intergeneracional de clase, omitimos la inclusión de variables de tipo temporal en el análisis, como son el año de encuesta o las cohortes de nacimiento. 
Utilizamos un agrupamiento de macro-clases basado en el esquema CASMIN (Comparative Analysis of Social Mobility in Industrial Nations) propuesto por Erikson y Goldthorpe (1992), con algunas modificaciones realizadas por el conjunto de investigadores que trabajaron en la investigación comparativa de Solís y Boado (2016). El principal reajuste del esquema consistió en remover de la categoría de trabajadores por cuenta propia a los trabajadores en ocupaciones manuales de baja calificación típicas del sector informal (por ejemplo, vendedores ambulantes, trabajadores domésticos o trabajadores en servicios personales no calificados), reagrupándolos en la clase de trabajadores manuales no calificados.

Dadas las limitaciones del tamaño muestral, que impiden trabajar con un esquema desagregado de clases, utilizamos un esquema resumido con cuatro macro-clases que supone un ordenamiento jerárquico de las mismas, lo que permite examinar la direccionalidad ascendente o descendente de la movilidad intergeneracional de clase (cuadro 1). Este esquema recupera la propuesta de tres macro-clases de Erikson y Goldthorpe (1992) para examinar la movilidad vertical, aunque aquí separamos a la clase de trabajadores manuales calificados de otros trabajadores manuales y agrícolas, debido a que tiene condiciones laborales y de ingresos sustancialmente mejores $y$, por lo tanto, implica un primer escalón en el ascenso social desde la base de la estructura de clases.

Medimos la escolaridad de dos maneras: como variable continua, es decir, como años de educación formal (de 0 a 24 años) y, en el caso de los análisis de ecualización y atenuación, que requieren variables categóricas, como una variable ordinal en cinco grupos: 1) hasta primaria completa, 2) secundaria incompleta, 3) secundaria completa, 4) superior incompleta y 5) superior (terciaria o universitaria) completa. En algunos análisis utilizamos sólo los niveles completos.

Con respecto a los modelos estadísticos, a cada uno de los efectos le corresponden modelos diferentes. Con respecto a los efectos de mediación, el análisis de trayectorias tradicional (path analysis) propuesto por Blau y Duncan supone la utilización exclusiva de variables continuas de intervalo o razón. Sin embargo, aquí pretendemos analizar el papel mediador de la escolaridad en la asociación entre orígenes y destinos de la clase social, que, como recién describimos, es una variable categórica ordinal. Para ello, utilizamos el análisis de mediación KHB propuesto por Breen, Karlson y Holm (2013). Este análisis fue desarrollado para comparar los coeficientes de dos modelos de regresión logística anidados, el primero sin variables de mediación y el segundo con ellas. Su utilidad es que permite descomponer el efecto total de una variable en su componente directo e indirecto, tal como lo hace el análisis de trayectorias tradicional. En este caso, utilizaremos un modelo de regresión logística ordenada, con la clase de destino como variable dependiente, la clase de origen como variable independiente y los años de escolaridad como variable de mediación.

Con respecto al efecto ecualizador, para establecer medidas comparativas entre países en ambas relaciones (OE) y (ED), aplicamos tres modelos loglineales de diferencias uniformes (Unidiff) (Erikson and Goldthorpe 1992; Xie 1992) con el país como variable de comparación. El primer modelo evalúa la intensidad de la asociación neta entre orígenes y destinos (OD) por país, como referente del nivel general de fluidez social. El segundo modelo mide la desigualdad de oportunidades educativas (OE) y el tercero los retornos de clase de la escolaridad (ED).

\section{Cuadro 1.}

Esquema de clases CASMIN y esquema de cuatro macro-clases

\section{Once clases}

Cuatro macro-clases

I. Empresarios medianos, directivos altos y profesionales superiores

II. Directivos medios, profesionales de nivel inferior y técnicos superiores

I. Clase de servicios y pequeños empresarios

Va. Pequeños empleadores (1 a 5 empleados)

IIIa. Empleados de oficina

IIIb. Empleados de comercio

IVb. Comerciantes y artesanos por cuenta propia

II. Clase de empleados no manuales y comerciantes o artesanos de oficio

V. Técnicos inferiores y supervisores manuales

VI. Obreros calificados y semicalificados

III. Clase de trabajadores manuales calificados

VIIa. Trabajadores manuales no calificados

Ivc. Pequeños propietarios agrícolas

VIIb. Trabajadores asalariados agrícolas
IV. Clase de trabajadores manuales no calificados y agrícolas

Fuente: elaboración propia. 
Finalmente, para establecer si la escolaridad atenúa la asociación entre orígenes y destinos de clase es necesario evaluar la magnitud de esta asociación en distintos niveles de escolaridad. Si a mayor escolaridad esta asociación decrece, entonces podremos concluir que el incremento en la escolaridad atenúa la influencia de los orígenes en los destinos alcanzados. En términos empíricos, esta hipótesis puede evaluarse nuevamente con modelos Unidiff de tres vías, en los que se evalúa la intensidad neta de la asociación entre orígenes y destinos de clase (OD) para distintos niveles de escolaridad.

Hasta hace no mucho tiempo, la investigación sobre movilidad social intergeneracional en AL excluyó a las mujeres bajo distintos argumentos, entre ellos, que su participación en el mercado de trabajo era mínima o que la posición de clase de las mujeres era determinada por la del jefe económico de la familia (habitualmente, un varón). Una nueva corriente de estudios ha buscado corregir este sesgo androcéntrico, incorporando análisis específicos para mujeres. En este trabajo nos apegamos a esta nueva corriente, lo cual nos permite identificar posibles diferencias de género en el papel mediador, ecualizador y atenuante de la escolaridad en la asociación entre orígenes y destinos de clase. Todos los modelos propuestos se ajustan por separado para varones y mujeres.

\section{Niveles de escolaridad Y CAMBios en LA ESTRUCTURA DE CLASES}

En AL, Argentina destacó por una expansión más temprana del nivel educativo primario y un mayor peso de la educación pública gratuita. Hasta fines de la década de 1950, el sistema educativo argentino se caracterizó por una cobertura amplia y homogénea en términos de calidad que, en el marco de una economía dinámica, brindaba amplias oportunidades de ascenso social (Tiramonti 2003). La expansión de la escolaridad secundaria fue anterior en Chile: en la década de 1980 el $50 \%$ de los adolescentes lograba finalizar la escuela secundaria; en Argentina este porcentaje se alcanzó en la década de 1990 y en México, en la actualidad, ronda el 45 \% (Bellei 2013). Por su parte, Chile y México tuvieron tasas de expansión de los niveles de escolaridad primaria y secundaria mayores entre 1980 y 2000, lo cual generó que en la primera década del siglo XXI los tres países acortaran distancias; incluso Chile ha sobrepasado a Argentina en el acceso a mayores niveles de escolaridad.

Los tres países tienen rasgos distintivos que resaltan la importancia de comparar el efecto de la escolaridad en la movilidad intergeneracional de clase. Chile tiene el sistema de educación más privatizado y segregado, especialmente en el nivel medio (Valenzuela et al. 2014), pero, al mismo tiempo, es el que más ha incrementado el nivel de escolaridad de la población. Argentina y México comparten una tra- dición de educación pública y gratuita en los tres niveles de escolaridad, pero en Argentina la expansión de la escolaridad primaria y secundaria fue anterior $y$, por lo tanto, el nivel de escolaridad de la población en la actualidad es mayor; en México, por su parte, partiendo de niveles de escolaridad inferior, el ritmo de la expansión de estos niveles fue mayor entre 1980 y la actualidad (Bellei 2013).

La gráfica 2 presenta una fotografía de la distribución por niveles educativos de la población ocupada en los tres países, de acuerdo a los resultados de las encuestas utilizadas. En la población masculina, Chile presenta el resultado más positivo: el mayor porcentaje que finalizó el nivel superior (19\%), seguido por Argentina (16\%) y luego por México (11 $\%$ ). En cambio, en la población femenina, Argentina exhibe el resultado más favorable: $27 \%$ tiene estudios superiores finalizados, seguido por Chile $(20 \%)$ y luego, a una distancia amplia, por México (11\%). En Argentina y México, tanto en varones como en mujeres, el porcentaje con estudios superiores incompletos es muy alto, alrededor del doble que en Chile. Mientras México y Chile tienen tasas parejas de logro de credenciales de nivel superior según sexo, en Argentina la disparidad es alta: 11 puntos porcentuales (p.p.) mayor entre las mujeres.

El segundo aspecto destacado en Chile es la finalización del nivel secundario sin proseguir estudios superiores, más de 10 p.p. mayor que en México y Argentina. Estos resultados sugieren que en Chile, donde el sistema está más privatizado y los mecanismos de premios y castigos más desarrollados (Villalobos y Quaresma 2015), el costo de oportunidad de cursar un nivel y no finalizarlo es mayor.

Por último, para ambos sexos en los tres países, entre un cuarto y un tercio de la población no logró estudios secundarios. En la franja poblacional que es objeto de nuestro estudio no se erradicaron pautas históricas de déficits educacionales que afectan especialmente a la población residente en regiones estancadas y en núcleos de marginalidad de las grandes ciudades. Esto representa una fuerte asimetría en relación con los países más industrializados.

En paralelo, se dio también un cambio en la estructura de clases que facilitó la movilidad intergeneracional ascendente de tipo estructural (cuadro 2). Entre los varones de Chile y México, este cambio se explica fundamentalmente por la expansión de la clase de servicios y pequeños empresarios (+11.2 p.p. $y+12.7$ p.p., respectivamente) y la contracción de la clase de trabajadores manuales no calificados y agrícolas (-12.8 p.p. y -18.3 p.p.). En Argentina el patrón es un poco más complejo, ya que partió de una clase de servicios relativamente amplia, que sólo experimentó una pequeña expansión (+3.7 p.p.), mientras que la clase intermedia de empleados no manuales y comerciantes y trabajadores calificados por cuenta propia fue la que más creció (+9 p.p.). 
Gráfica 2.

Nivel de escolaridad, por país de residencia y sexo, personas ocupadas entre 25 y 64 años de edad (en \%)

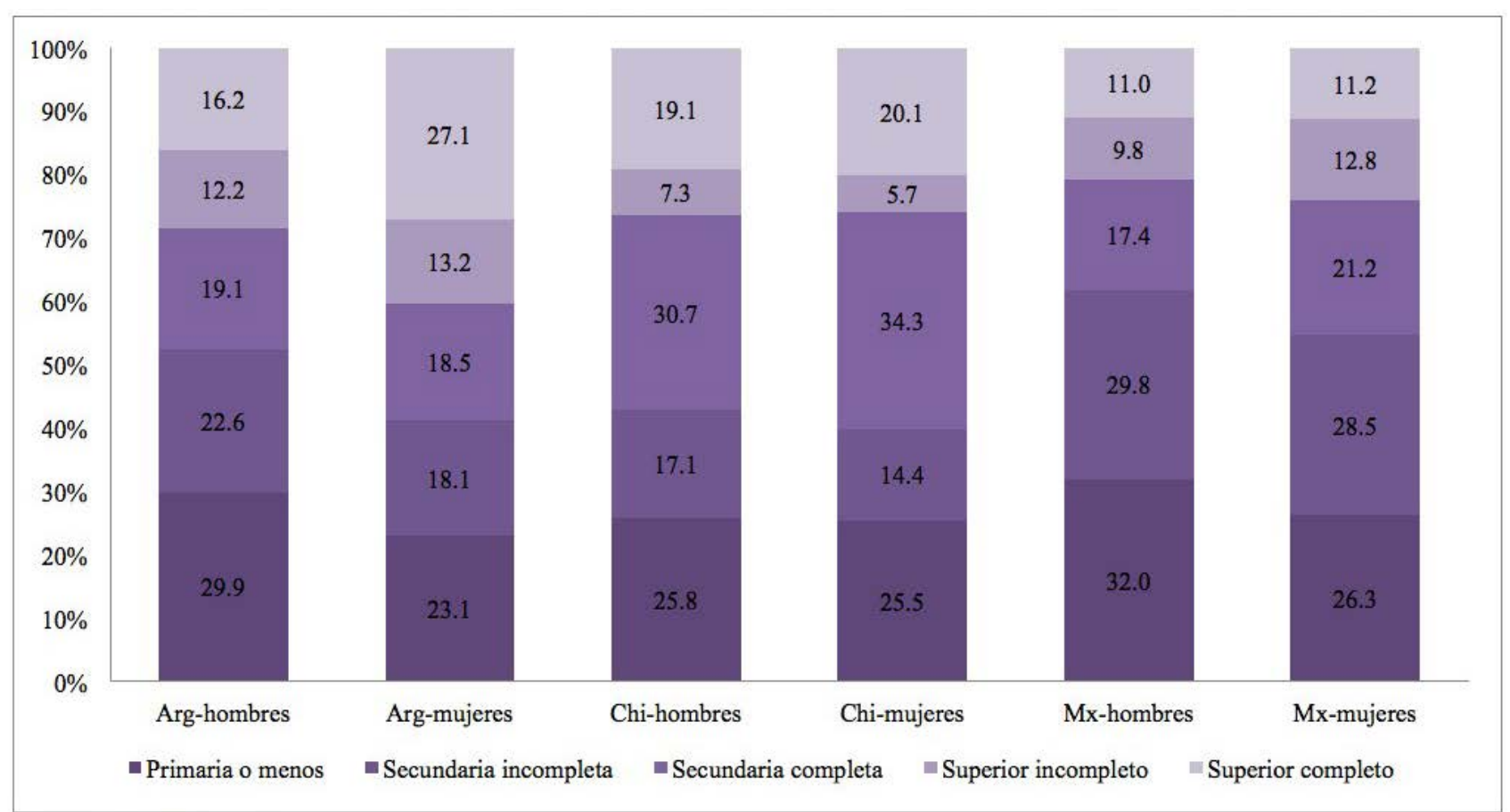

Fuente: estimaciones propias.

Cuadro 2.

Distribución por "macro-clases" en Argentina, Chile y México y cambios marginales con respecto a la distribución en orígenes, por sexo

\begin{tabular}{|c|c|c|c|c|c|c|}
\hline & \multicolumn{2}{|c|}{ Argentina } & \multicolumn{2}{|c|}{ Chile } & \multicolumn{2}{|c|}{ México } \\
\hline & & $\Delta$ con & & $\Delta$ con & & $\Delta$ con \\
\hline & $\%$ & origenes & $\%$ & orígenes & $\%$ & orígenes \\
\hline \multicolumn{7}{|l|}{ a) Hombres } \\
\hline Clase de servicios y pequeños empresarios & 22.7 & +3.7 & 23.5 & +11.2 & 22.3 & +12.7 \\
\hline \multicolumn{7}{|l|}{ Empleados no manuales, comerciantes o trabajadores calif. por } \\
\hline cuenta propia & 22.0 & +9.0 & 14.2 & +3.2 & 21.2 & $+2-0$ \\
\hline Obreros calificados & 22.9 & -3.6 & 21.3 & -1.6 & 15.4 & +3.6 \\
\hline Trabajadores manuales no calificados y agrícolas & 32.4 & -9.1 & 41.0 & -12.8 & 41.1 & -18.3 \\
\hline Total & 100.00 & --- & 100.00 & --- & 100.00 & --- \\
\hline Número de casos & 1570 & $-\ldots$ & 1203 & 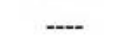 & 3934 &.-- \\
\hline \multicolumn{7}{|l|}{ b) Mujeres } \\
\hline Clase de servicios y pequeños empresarios & 28.4 & +8.6 & 22.6 & +12.1 & 23.4 & +11.3 \\
\hline Empleados no manuales, comerciantes o trabajadores calif. por & & & & & & \\
\hline cuenta propia & 28.5 & +12.4 & 24.4 & +14.3 & 40.5 & +17.6 \\
\hline Obreros calificados & 6.6 & -14.4 & 9.0 & -12.4 & 7.2 & -3.2 \\
\hline Trabajadores manuales no calificados y agrícolas & 36.5 & -6.6 & 44.0 & -14.0 & 28.9 & -25.7 \\
\hline Total & 100.00 & --- & 100.00 & $-\ldots$ & 100.00 & --- \\
\hline Número de casos & 1112 & 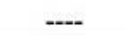 & 966 & -.- & 1721 & -..- \\
\hline
\end{tabular}

Fuente: elaboración propia.

Entre las mujeres, el cambio intergeneracional en las estructuras de clase es mayor, pero esto, como se ha señalado en otra parte (Solís y Boado 2016), se explica en parte por la segregación ocupacional por sexo. La expansión se reparte de manera más equitativa entre la clase de servicios y pequeños empleadores y la clase de empleados no manuales y comerciantes y trabajadores calificados por cuenta propia (con ganancias conjuntas de +20 p.p. en los tres países), mientras que la contracción acontece tanto entre la clase manual calificada (por las barreras que enfrentan las mujeres para acceder a ocupaciones obreras) y la clase de trabajadoras manuales no calificadas.

Estos cambios apuntan hacia una expansión conjunta de la escolaridad y de una de las clases que agrupan a las ocupaciones de mayor calificación, aunque con ritmos y énfasis diferentes en cada país. Por otra parte, cuando se comparan las estructuras 
de clases con los países de industrialización temprana, resulta evidente que la expansión de la clase de servicios es todavía incipiente en comparación con ellos (Solís y Boado 2016).

La expansión de la escolaridad ha acontecido en un contexto de persistente desigualdad de oportunidades educativas. Aunque más tarde profundizaremos en este problema, una exploración descriptiva de la distribución de las personas entrevistadas por origen de clase y destino educativo nos coloca en perspectiva (cuadro 3). Los logros educativos son mayores en las clases de mayor jerarquía. Así, por ejemplo, la probabilidad de terminar la educación superior para quienes provienen de la clase de servicios y pequeños empresarios en Argentina es del $43 \%$, frente al $9.6 \%$ de los hijos de trabajadores manuales no calificados, una chance 4.5 veces mayor. Esta brecha es 7.7 veces mayor en Chile y 4.1 veces mayor en México. En contraste, el riesgo de no rebasar la educación básica es $7.1,15.4$ y 4.9 veces menor, respectivamente.

Las pautas de expansión de la escolaridad y de las clases que agrupan a las ocupaciones de mayor calificación sugieren que la escolaridad podría ser un canal importante de movilidad social ascendente. Sin embargo, la amplia desigualdad de logro educativo según orígenes de clase nos lleva nuevamente al interrogante fundamental de nuestro estudio: ¿cuál es el papel de la escolaridad en la asociación entre orígenes y destinos de clase en los tres países?

\section{LA ESCOLARIDAD COMO MEDIADOR}

En esta sección analizamos el efecto mediador de la escolaridad en la asociación entre orígenes y destinos de clase a través de los modelos logísticos ordenados KHB (cuadro 4). Presentamos primero el efecto total, que estima la brecha en momios de ascenso de clase para todos los contrastes entre las clases de origen; comparamos luego con el efecto directo, aquél que permanece una vez descontada la mediación de la escolaridad. EI contraste de estos dos efectos permite estimar la mediación de la escolaridad como un porcentaje del efecto total. Además de los coeficientes para cada contraste, presentamos los promedios para cada modelo, lo que permite hacer una evaluación general de su intensidad.

Destacamos cinco conclusiones. En primer lugar, los efectos totales de la clase social de origen sobre los momios de alcanzar una clase de mayor jerarquía son de una magnitud similar en los tres países, con promedios entre 3.2 y 3.9. La única excepción son las mujeres en México, donde los efectos son menores, con promedio de 2.3. Esto es consistente con los resultados de investigaciones previas, que muestran que México es el único de los tres países en donde la asociación neta entre orígenes y destinos de clase es menor entre las mujeres, probablemente debido a la mayor selectividad de su participación laboral (Solís y Boado 2016).

En segundo lugar, las mayores brechas corresponden al contraste entre la clase de servicios y pequeños empleadores (clase 1) y la clase de trabajadores manuales no calificados y agrícolas (clase 4). Los momios de alcanzar una clase de mayor jerarquía son mayores entre 6.7 veces (mujeres en México) y 20.0 veces (Mujeres en Argentina y hombres en Chile) para la clase 1 con relación a la clase 4. Le sigue en intensidad la brecha entre la clase de

Cuadro 3.

Distribución de nivel de escolaridad por "macro-clases" de origen, Argentina, Chile y México

\begin{tabular}{|c|c|c|c|c|c|c|}
\hline & Primaria & $\begin{array}{l}\text { Secundaria } \\
\text { incompleta }\end{array}$ & $\begin{array}{c}\text { Secundaria } \\
\text { completa }\end{array}$ & $\begin{array}{c}\text { Superior } \\
\text { incompleta }\end{array}$ & $\begin{array}{l}\text { Superior } \\
\text { completa }\end{array}$ & Total \\
\hline \multicolumn{7}{|l|}{ a) Argentina } \\
\hline Clase de servicios y pequeños empresarios & 6.2 & 14.3 & 13.6 & 23.0 & 43.0 & 100.0 \\
\hline \multicolumn{7}{|c|}{ Empleados no manuales, comerciantes o trabajadores calif. por } \\
\hline cuenta propia & 13.7 & 18.2 & 29.1 & 13.7 & 25.2 & 100.0 \\
\hline Obreros calificados & 22.4 & 24.5 & 20.6 & 12.4 & 20.0 & 100.0 \\
\hline Trabajadores manuales no calificados y agrícolas & 43.8 & 22.2 & 16.8 & 7.5 & 9.6 & 100.0 \\
\hline \multicolumn{7}{|l|}{ b) Chile } \\
\hline Clase de servicios y pequeños empresarios & 2.5 & 7.1 & 13.3 & 13.1 & 64.0 & 100.0 \\
\hline \multicolumn{7}{|c|}{ Empleados no manuales, comerciantes o trabajadores calif. por } \\
\hline cuenta propia & 15.4 & 15.5 & 28.1 & 11.2 & 29.8 & 100.0 \\
\hline Obreros calificados & 15.7 & 17.4 & 41.6 & 9.1 & 16.2 & 100.0 \\
\hline Trabajadores manuales no calificados y agrícolas & 38.6 & 18.2 & 31.6 & 3.3 & 8.3 & 100.0 \\
\hline \multicolumn{7}{|l|}{ c) México } \\
\hline Clase de servicios y pequeños empresarios & 8.5 & 13.4 & 19.3 & 30.0 & 28.8 & 100.0 \\
\hline \multicolumn{7}{|c|}{ Empleados no manuales, comerciantes o trabajadores calif. por } \\
\hline cuenta propia & 15.4 & 31.9 & 22.9 & 14.5 & 15.4 & 100.0 \\
\hline Obreros calificados & 13.0 & 41.2 & 30.4 & 7.9 & 7.5 & 100.0 \\
\hline Trabajadores manuales no calificados y agrícolas & 42.1 & 29.0 & 15.1 & 6.8 & 7.1 & 100.0 \\
\hline
\end{tabular}

Fuente: elaboración propia. 


\section{Cuadro 4.}

Resultados de modelos logísticos ordenados KHB para la asociación entre orígenes y destinos de clase, con la mediación de los años de escolaridad, por país y sexo

\begin{tabular}{|c|c|c|c|c|c|c|}
\hline & \multicolumn{3}{|c|}{ Hombres } & \multicolumn{3}{|c|}{ Mujeres } \\
\hline & \multicolumn{2}{|c|}{ Razones de momios /1 } & $\begin{array}{c}\text { Mediación de } \\
\text { escolaridad (\%) }\end{array}$ & \multicolumn{2}{|c|}{$\begin{array}{c}\text { Razones de momios } / 1 \\
\text { Efecto total Efecto directo }\end{array}$} & $\begin{array}{c}\text { Mediación de } \\
\text { escolaridad (\%) }\end{array}$ \\
\hline \multicolumn{7}{|l|}{ a) Argentina } \\
\hline Clase 1 vs. 2 & $3.3^{*}$ & 1.4 & 72.9 & $3.7^{*}$ & $1.7^{*}$ & 59.4 \\
\hline Clase 1 vs. 3 & $5.9^{*}$ & $1.9^{*}$ & 64.2 & $5.9^{*}$ & 1.5 & 76.0 \\
\hline Clase 1 vs. 4 & $12.5^{*}$ & $2.1^{*}$ & 70.7 & $20.0^{*}$ & $1.8^{*}$ & 80.0 \\
\hline Clase 2 vs, 3 & $1.7^{*}$ & 1.3 & 45.3 & 1.5 & 0.9 & 127.2 \\
\hline Clase 2 vs. 4 & $3.7^{*}$ & 1.5 & 68.6 & $5.0^{*}$ & 1.1 & 96.8 \\
\hline Clase 3 vs. 4 & $2.1^{*}$ & 1.1 & 86.0 & $3.3^{*}$ & 1.2 & 86.0 \\
\hline Promedios & 3.2 & 1.5 & 68.0 & 3.7 & 1.3 & 87.6 \\
\hline Número de casos & \multicolumn{3}{|c|}{1564} & \multicolumn{3}{|c|}{1110} \\
\hline Pseudo R2 (McFadden) & \multicolumn{3}{|c|}{0.20} & \multicolumn{3}{|c|}{0.30} \\
\hline \multicolumn{7}{|l|}{ b) Chile } \\
\hline Clase 1 vs. 2 & $3.7^{*}$ & 1.8 & 55.1 & $3.2^{*}$ & 1.0 & 100.7 \\
\hline Clase 1 vs. 3 & $6.3^{*}$ & $2.2^{*}$ & 55.3 & $5.6^{*}$ & 1.5 & 77.7 \\
\hline Clase 1 vs. 4 & $20.0^{*}$ & $4.0^{*}$ & 54.9 & $12.5^{*}$ & $2.0^{*}$ & 72.1 \\
\hline Clase 2 vs. 3 & $1.7^{*}$ & 1.3 & 55.8 & 1.7 & 1.5 & 25.3 \\
\hline Clase 2 vs. 4 & $5.9^{*}$ & $2.2^{*}$ & 54.7 & $4.0^{*}$ & $2.0^{*}$ & 47.5 \\
\hline Clase 3 vs. 4 & $3.4^{*}$ & $1.8^{*}$ & 54.3 & $2.4^{*}$ & 1.4 & 61.0 \\
\hline Promedios & 3.9 & 1.9 & 55.0 & 3.3 & 1.5 & 64.1 \\
\hline Número de casos & \multicolumn{3}{|c|}{1152} & \multicolumn{3}{|c|}{919} \\
\hline Pseudo R2 (McFadden) & \multicolumn{3}{|c|}{0.17} & \multicolumn{3}{|c|}{0.19} \\
\hline \multicolumn{7}{|l|}{ c) México } \\
\hline Clase 1 vs. 2 & $2.4^{*}$ & 1.4 & 60.9 & $3.6^{*}$ & $1.9^{*}$ & 51.6 \\
\hline Clase 1 vs. 3 & $5.0^{*}$ & $2.4^{*}$ & 44.9 & $5.0^{*}$ & $2.4^{*}$ & 44.6 \\
\hline Clase 1 vs. 4 & $11.1^{*}$ & $3.1^{*}$ & 51.4 & $6.7^{*}$ & $1.9^{*}$ & 67.1 \\
\hline Clase 2 vs. 3 & $2.0^{*}$ & $1.7^{*}$ & 24.5 & 1.4 & 1.3 & 18.3 \\
\hline Clase 2 vs. 4 & $4.3^{*}$ & $2.2^{*}$ & 45.6 & $1.9^{*}$ & 1.0 & 97.4 \\
\hline Clase 3 vs. 4 & $2.1^{*}$ & 1.3 & 64.9 & 1.4 & 0.8 & 184.8 \\
\hline Promedios & 3.2 & 1.8 & 48.7 & 2.3 & 1.3 & 77.3 \\
\hline Número de casos & \multicolumn{3}{|c|}{3934} & \multicolumn{3}{|c|}{1721} \\
\hline Pseudo R2 (McFadden) & \multicolumn{3}{|c|}{0.13} & \multicolumn{3}{|c|}{0.17} \\
\hline
\end{tabular}

/ $1 \mathrm{El}$ efecto total incluye el efecto directo e indirecto a través de la escolaridad, el efecto directo corresponde al efecto una vez eliminada la asociación indirecta a través de la escolaridad

$* \mathrm{p}<0.05$

Fuente: estimaciones propias.

servicios y la manual calificada (razones de momios entre 5.0 y 6.3). Esto nuevamente es consistente con resultados previos que enfatizan las amplias distancias sociales entre las clases de origen extremas en oportunidades de movilidad social intergeneracional (Torche 2005; Solís y Boado 2016; Dalle 2018; Benza 2012).

En tercer lugar, la magnitud de las razones de momios se reduce sustancialmente al contrastar los efectos directos con los totales, e incluso varias razones de momios pierden significancia estadística. Los efectos de mediación son, en promedio, al menos cercanos al $50 \%$, o incluso mayores. Es decir, tal como lo señalaron los estudios de logro de estatus, así como la investigación más reciente, la mayor parte del efecto del origen de clase en la movilidad se ejerce vía la mediación de la escolaridad.

La cuarta conclusión es que la intensidad del efecto mediación varía sustancialmente por sexo. La escolaridad tiene un mayor efecto mediador para las mujeres, con diferencias en promedio que van de 9 puntos porcentuales en Chile (64.1\% vs. $55.0 \%$ ) a 
29 puntos en México (77.3 \% vs. $48.7 \%$ ). Esto implica que existe una asociación directa relativamente débil entre la clase de los padres y las hijas, siendo la desigualdad de oportunidades educativas el principal componente de la transmisión intergeneracional de las posiciones de clase.

Por último, al comparar entre países, el efecto mediador de la escolaridad es mayor en Argentina, lo que nuevamente apunta al mayor peso de la escolaridad en los procesos de transmisión intergeneracional de la desigualdad y al hecho de que la asociación directa entre orígenes y destinos, una vez controlada la mediación de la escolaridad, parece ser menor en Argentina.

En síntesis, la escolaridad es un importante mediador, aunque no alcanza a dar cuenta por completo de los efectos de los orígenes sobre los destinos de clase. También podemos concluir que el efecto mediador es mayor para las mujeres y también para Argentina en relación con los otros dos países. Como ya discutimos, este poderoso efecto mediador no implica necesariamente que exista una menor asociación total entre orígenes y destinos de clase, que la escolaridad sea un ecualizador de oportunidades ni mucho menos un atenuante de la asociación entre orígenes y destinos. Estas últimas dos cuestiones las revisaremos enseguida.

\section{LA ESCOLARIDAD COMO ECUALIZADOR}

La escolaridad suele ser considerada como canal de movilidad social, pero, al mismo tiempo, como ya vimos, se distribuye de manera desigual según los orígenes de clase. Esta tensión constitutiva está presente en todas las sociedades. Sin embargo, como ya discutimos, para que la escolaridad sea un canal de movilidad ascendente es necesario nivelar el terreno (disminuir la desigualdad de oportunidades educativas), de modo que quienes provienen de clases de menor jerarquía tengan las mismas chances de logros educativos. Simultáneamente, se requiere que la escolaridad rinda beneficios en términos del acceso a posiciones ocupacionales de mayor jerarquía.

Hemos apuntado que, en términos empíricos, esto implica una baja o nula asociación OE y una alta asociación ED. Con el objetivo de indagar en clave comparativa el papel ecualizador de la escolaridad en los tres países, aplicamos modelos loglineales Unidiff que nos permiten evaluar en términos comparativos la intensidad neta de estas asociaciones. Esta intensidad se resume en los parámetros Phi (cuadro 5).

En primer lugar, para los varones, la intensidad neta de la asociación OD es mayor en Chile ( $\varnothing$ $=1.25$ ), mientras que entre las mujeres no existen diferencias significativas. En segundo lugar, la asociación OE también es mayor en Chile $(\varnothing=1.55)$, mientras que México $(\varnothing=1.18)$ está en una situación intermedia, aunque más cercano a Argentina. Al contrastar la bondad de ajuste con el modelo de asociación constante se observa que las diferencias entre países son significativas. Las pruebas de razón de verosimilitud (LR) son significativas con $p<0,05$ y también se reducen el índice de disimilitud y el BIC. En el caso de las mujeres, los resultados indican que las diferencias entre países no son significativas.

Por último, la asociación neta ED es mayor para varones y mujeres en Argentina. Entre los varones, Chile y México tienen niveles de asociación pareci-

Cuadro 5.

Resultados de modelos loglineales de diferencias uniformes (Unidiff) por país, origen de clase-destino de clase, origen de clase-escolaridad, y escolaridad-destino de clase

\begin{tabular}{|c|c|c|c|c|c|c|}
\hline & \multicolumn{6}{|c|}{ Parámetros Phi (escalados con Argentina=1) } \\
\hline & \multicolumn{2}{|c|}{ Origen - Destino (OD) } & \multicolumn{2}{|c|}{ Origen-Escolaridad (OE) } & \multicolumn{2}{|c|}{ Escolaridad-Destino (ED) } \\
\hline & Hombres & Mujeres & Hombres & Mujeres & Hombres & Mujeres \\
\hline Argentina (referencia) & 1 & 1 & 1 & 1 & 1 & 1 \\
\hline Chile & 1.25 & 1.05 & 1.55 & 1.06 & 0.81 & 0.70 \\
\hline \multirow[t]{4}{*}{ México } & 1.01 & 0.78 & 1.18 & 0.98 & 0.84 & 0.98 \\
\hline & \multicolumn{6}{|c|}{ Pruebas de bondad de ajuste $/ 1$} \\
\hline & \multicolumn{2}{|c|}{ Origen - Destino (OD) } & \multicolumn{2}{|c|}{ Origen-Escolaridad (OE) } & \multicolumn{2}{|c|}{ Escolaridad-Destino (ED) } \\
\hline & Hombres & Mujeres & Hombres & Mujeres & Hombres & Mujeres \\
\hline Prueba LR (2 g.l.) & 7.3* & 5.4 & $14.7^{*}$ & 0.5 & $11.7 *$ & $25.3^{*}$ \\
\hline Cambio en índice de disimilitud & -0.5 & -0.3 & -0.4 & -0.1 & -0.4 & -0.7 \\
\hline Cambio en BIC & 10.2 & 11.0 & -6.9 & 16.0 & -6.0 & -8.8 \\
\hline
\end{tabular}


$\operatorname{dos}(\varnothing=0.81$ y 0.84 , respectivamente). Para las mujeres, Argentina y México presentan mayores retornos a la escolaridad que Chile $(\varnothing=0.70)$. En ambos casos, las medidas de bondad de ajuste nos hacen elegir con claridad el modelo de diferencias uniformes, es decir, el modelo que postula retornos de la escolaridad disímiles entre países.

¿Qué sugieren estos resultados con relación al efecto ecualizador de la escolaridad? Este efecto es comparativamente mayor para los varones en Argentina, donde existe menor desigualdad de oportunidades educativas (OE más bajo) y mayores retornos a la escolaridad (ED más alto). México se ubica en una situación intermedia. En el otro extremo, la escolaridad tiene un papel menor como ecualizador entre los varones de Chile, ya que presentan valores mayores en la asociación OE (mayor desigualdad de oportunidades educativas) y también menores retornos educativos (ED). La alta desigualdad de oportunidades educativas, sumada a mayores efectos directos de los orígenes de clase (ver cuadro 3 ), son los factores que explican la mayor asociación total OD entre los varones chilenos.

Por último, entre las mujeres la desigualdad de oportunidades educativas es constante en los países estudiados y no se advierten grandes diferencias en el nivel de fluidez social (quizás México podría ser un poco más fluido). Destaca, sin embargo, que las mujeres de Chile presentan menores retornos de la escolaridad, lo que sugiere que la escolaridad tiene un papel menos eficiente como ecualizador de oportunidades en Chile que en los otros dos países.

\section{LA ESCOLARIDAD COMO ATENUANTE}

Hemos visto que la escolaridad es un mediador clave en la asociación entre orígenes y destinos de clase. También que su papel ecualizador varía por país y entre hombres y mujeres. Pero, ¿en qué medida el acceso a mayores niveles de escolaridad abre un espacio para la meritocracia? Es decir, ¿en qué medida el incremento de la escolaridad disminuye el peso de la mochila del origen social en los destinos de clase?

En el cuadro 6 se observan los resultados de los modelos Unidiff con los que analizamos la asociación neta OD para tres niveles de escolaridad en cada país y sexo ${ }^{2}$. La intensidad de esta asociación se refleja en la magnitud del parámetro $(\varnothing)$ según niveles de escolaridad. Hemos fijado como grupo de referencia el nivel menor de escolaridad ("Hasta primaria completo"), al que corresponde entonces un $\varnothing=1$. Si $\varnothing$ es menor que 1 en los niveles mayores de escolaridad, esto indicaría una asociación más débil y es evidencia en favor de la hipótesis de atenuación. Al igual que antes, utilizamos medidas de bondad de ajuste para contrastar el modelo Unidiff con un modelo más simple que postula ausencia de diferencias asociadas a la escolaridad.

\section{Cuadro 6.}

Resultados de modelos loglineales de diferencias uniformes (Unidiff) para la asociación entre orígenes y destinos de clase, por niveles de escolaridad, según país y sexo

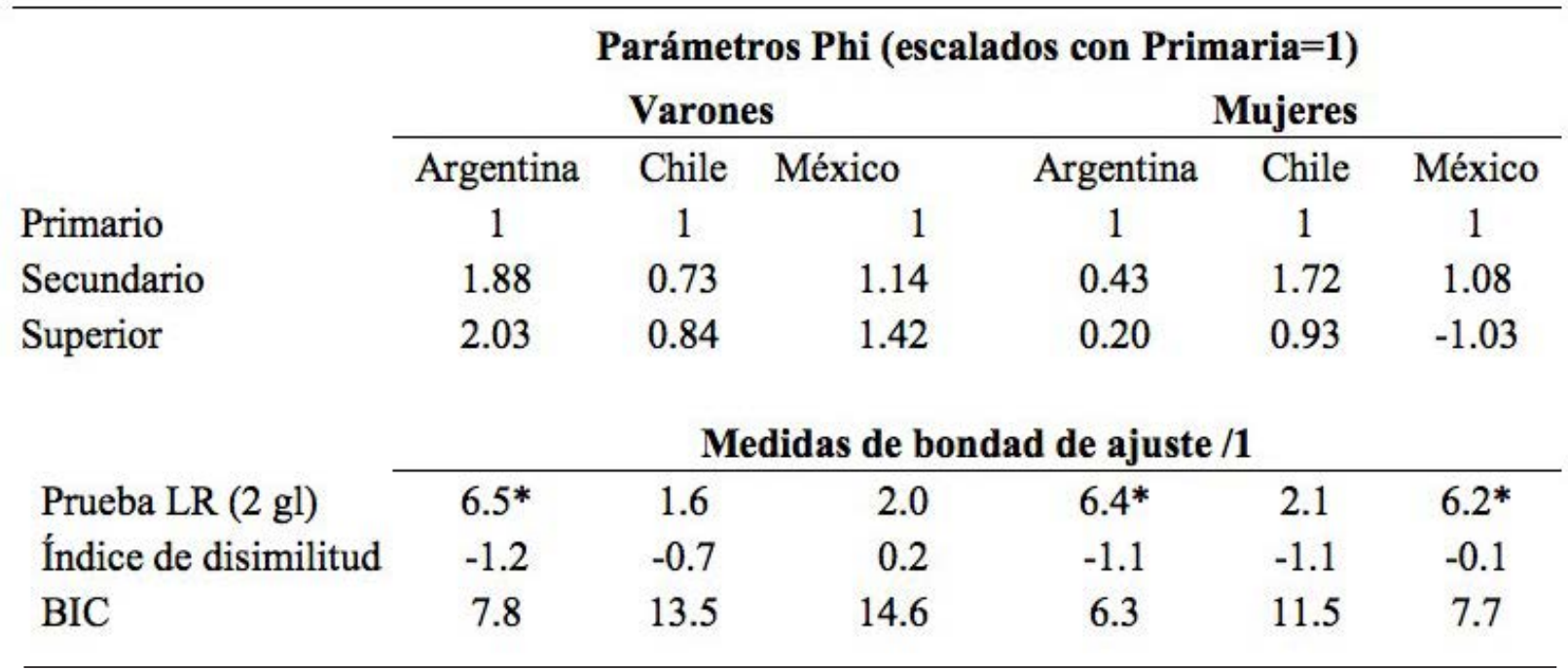

/1 En comparación con el modelo de asociación constante

$* \mathrm{p}<0.1$

$* * \mathrm{p}<0.05$

Fuente: estimaciones propias. 
Contrario a la hipótesis de meritocratización, la asociación neta OD aumenta con la escolaridad para los varones de Argentina $(\varnothing=1.88$ en el nivel secundario y $\varnothing=2.02$ en el nivel superior). El modelo Unidiff exhibe mejoras modestas en el ajuste de los datos. Contrastando su bondad de ajuste con el modelo de fluidez constante, es posible observar una disminución del LR de 6.5, significativa al $p<0.10$ y una reducción del índice de disimilitud de 1.2. Esto nos lleva a preferir con recaudos el modelo Unidiff y respaldar los resultados de trabajos previos (Jorrat 2016).

En el extremo opuesto, entre las mujeres de Argentina y de México hay indicios de mayor fluidez a medida que aumenta la escolaridad $(\varnothing=0.43$ en el nivel secundario y $\varnothing=0.20$ en el nivel superior en Argentina y, de manera muy marcada, entre las mujeres de México que egresaron del nivel superior $\varnothing=-1.03)$. En ambos casos, las medidas de bondad de ajuste nos permiten con cautela preferir la hipótesis de diferencias significativas en relación con la hipótesis de asociación constante. La disminución del LR es de 6.4 en las mujeres de Argentina y de 6.2 en las mujeres de México, significativas en ambos casos al $p<0.10$. La reducción del índice de disimilitud es mayor en las mujeres Argentina (1.1), mientras que en México casi no varía (-0.1). El valor de BIC tampoco presenta mejorías en ambos casos.

En los varones de Chile y México, los resultados respaldan al modelo de asociación constante. Sin embargo, si prestamos atención a los valores de $\varnothing$, la tendencia en ambos países sería distinta: mientras en los varones de Chile hay un ligero aumento de la fluidez social con el incremento de la escolaridad $(\varnothing=0.72$ en el nivel secundario y $\varnothing=0.84$ en el nivel superior); en los varones de México aumentan las rigidices, como en los varones de Argentina $(\varnothing=1.14$ en el nivel secundario y $\varnothing=1.42$ en el nivel superior), aunque no debemos olvidar que los indicadores de bondad de ajuste en ambos casos nos hacen preferir el modelo de asociación constante.

Por último, en las mujeres de Chile los resultados indican que las diferencias entre niveles educativos no son significativas: ajusta mejor el modelo de asociación constante.

\section{Discusión Y CONCLUSIONES}

Hemos analizado el papel de la escolaridad en la asociación entre orígenes y destinos de clase, con una perspectiva comparativa entre tres países de $A L$. El interrogante principal de la investigación sobre estratificación social en este ámbito es si la escolaridad es un canal privilegiado de nivelación de oportunidades o, por el contrario, contribuye a reproducir las desigualdades de origen.
Argumentamos que, para resolver este interrogante, es necesario distinguir entre tres efectos de la escolaridad: mediación, ecualización, y atenuación. Los estudios clásicos del modelo de logro de status demostraron que la escolaridad es un mediador importante del efecto de los orígenes sociales sobre los destinos ocupacionales. Sin embargo, esto no implica necesariamente que la escolaridad sea un ecualizador: para ello se requiere minimizar la desigualdad de oportunidades educativas y maximizar los rendimientos ocupacionales de la escolaridad. Más aun, la escolaridad puede ser atenuante si es que, al aumentar la escolaridad, los orígenes de clase pierden importancia como determinante de los destinos ocupacionales.

A partir de este planteamiento, propusimos medidas específicas para cada uno de estos tres efectos y las estimamos con encuestas nacionales de movilidad social para Argentina, Chile y México. A diferencia de aproximaciones previas, nuestro análisis adopta un enfoque de clases sociales, por lo que en lugar de utilizar medidas continuas de status ocupacional optamos por un esquema de macro-clases basado en la propuesta de Erikson y Goldthorpe.

Partimos de una descripción de los principales cambios en la escolaridad y la estructura de clases. Con relación a la escolaridad, se observan incrementos importantes, aunque Argentina presenta un estancamiento en la expansión de la educación superior, al punto de que fue superado por Chile, que ha logrado una mayor cobertura de los niveles secundario y superior y destaca también por sus tasas de finalización de dichos estudios. Con relación a estos dos países, México presenta rezagos importantes, particularmente en el acceso a la educación superior. Por su parte, la estructura de clases también tuvo cambios importantes, que apuntan a una ampliación de la clase de servicios, que agrupa a profesionales, gerentes y técnicos y, por tanto, demanda mayores niveles de escolaridad. Estos cambios se dieron en un contexto de persistente desigualdad por orígenes de clase en los niveles de escolaridad.

Para discutir los resultados del análisis de los efectos de mediación, ecualización y atenuación, preparamos el cuadro 7, que resume en clave comparativa los resultados. Con respecto a los efectos de mediación, encontramos que la mayor parte de la asociación entre orígenes y destinos de clase es mediada por la escolaridad. Este efecto mediador es mayor en Argentina. También es sustancialmente mayor entre las mujeres, lo cual sugiere que los efectos de la herencia de clase operan de forma indirecta (a través de la escolaridad) en la relación entre padres e hijas en mayor medida que en la relación entre padres e hijos. 
Cuadro 7.

Resumen de los efectos de la escolaridad en la asociación entre orígenes y destinos de clase en Argentina, Chile y México

\begin{tabular}{lccc} 
& Mediador & Ecualizador & Atenuante \\
\cline { 2 - 4 } a) Hombres & & & No (efecto opuesto) \\
Argentina & Mayor & Mayor & No \\
Chile & Menor & Menor & No \\
México & Intermedio & Intermedio & \\
b) Mujeres & & & Sí \\
Argentina & Mayor & --- & No significativo \\
Chile & Menor & Menor & Sí \\
México & Intermedio & --- &
\end{tabular}

Fuente: elaboración propia a partir de los resultados de los cuadros 4,5 y 6.

Por otra parte, al contrastar la fluidez social entre las clases de origen, se observa que la mediación de la escolaridad prácticamente absorbe la totalidad de las diferencias entre las clases contiguas e intermedias, pero no así entre las clases extremas. Es decir, aunque la mayor parte de la desigualdad en destinos asociada a las clases de origen es explicada por las brechas en logros educativos, la desigualdad en las oportunidades de movilidad social entre las clases extremas (trabajadores manuales y miembros de la clase de servicios) persiste incluso cuando se controla por la escolaridad. Esto es consistente con los estudios previos sobre los patrones de fluidez social en los países de $A L$, en tanto muestra que las barreras a la movilidad son mayores en los extremos de la estructura social, al grado de que estas barreras persisten incluso si descontamos los efectos de la escolaridad.

Aunque se observa un fuerte efecto de mediación, no puede afirmarse que en todos los casos la escolaridad tenga el mismo papel como ecualizador de oportunidades. La asociación entre orígenes de clase y escolaridad es menor y la asociación entre escolaridad y destinos de clase mayor entre los varones de Argentina, mientras que los varones de Chile se encuentran en el otro extremo y los de México en un punto intermedio. Al tener un menor efecto directo de los orígenes de clase, un acceso más igualitario a la escolaridad y mayores rendimientos de la escolaridad en términos de los destinos de clase, Argentina aparece, entonces, como el país en el que la escolaridad tiene un mayor efecto ecualizador para los varones, mientras que en Chile los efectos ecualizadores son menores. Por su parte, en el caso de las mujeres no hay muchas diferencias entre países en la asociación entre orígenes de clase y escolaridad, pero Chile presenta nuevamente menores rendimientos de la escolaridad, lo cual apunta otra vez a un menor efecto ecualizador de la escolaridad.
Finalmente, nuestro análisis de la escolaridad como atenuante se focalizó en la asociación entre orígenes y destinos de clase por niveles de escolaridad. En el caso de los varones no existe un efecto de atenuación. De hecho, en Argentina se presenta el efecto opuesto: en la medida en que se incrementa la escolaridad, el efecto de los orígenes sobre los destinos de clase también lo hace, mientras que en Chile y México no hay diferencias estadísticamente significativas. Por el contrario, entre las mujeres de Argentina y México se observa un claro efecto de atenuación, con mayor intensidad para el caso mexicano.

Es decir, a pesar de que los tres países latinoamericanos comparten ciertas similitudes en su expansión de las clases de servicios y no manual de rutina, así como incrementos en la escolaridad (aunque con variados ritmos e intensidades), difieren significativamente en el papel que juega la escolaridad en la movilidad intergeneracional de clase. Asimismo, el papel de la escolaridad parece ser distinto para varones y mujeres. Entre los varones, Argentina se encuentra mejor posicionada que México y Chile, en tanto la escolaridad tiene un mayor papel mediador y ecualizador. Sin embargo, es justo en este país donde la asociación entre orígenes y destinos, lejos de atenuarse, crece con la escolaridad. De este modo, parecería que entre los varones de Argentina existe una suerte de efecto compensación de la desigualdad de oportunidades que facilita el acceso a la escolaridad y maximiza sus rendimientos en términos de los destinos de clase, pero castiga en el mercado de trabajo a quienes provienen de clases desfavorecidas y logran altos niveles de escolaridad.

Por su parte, los varones de Chile, y también en alguna medida las mujeres, se encuentran en una situación de mayor desventaja, en tanto presentan la mayor desigualdad de oportunidades educativas, 
los menores rendimientos de la escolaridad y un nulo efecto atenuante de la escolaridad en la asociación entre orígenes y destinos de clase. Finalmente, la escolaridad parece tener claros efectos positivos entre las mujeres de Argentina y en México, no sólo por su papel ecualizador, sino también porque el acceso a la escolaridad opera claramente como un atenuante de la asociación entre orígenes y destinos de clase.

Nuestro material empírico no permite identificar los mecanismos que explican estas diferencias, lo cual es siempre una pieza faltante en los análisis macrosociales de movilidad social. No obstante, es probable que parte de la explicación se asocie a las variaciones institucionales en las condiciones de acceso a la escolaridad. Son claras, por ejemplo, las diferencias en el rumbo que han seguido Argentina, México y Chile en la administración de sus sistemas educativos. Mientras que Argentina privilegió un sistema educativo predominantemente público y gratuito, incluso en la educación superior, y México mantiene, a pesar del avance de las instituciones privadas, una presencia predominante de la educación pública en todos sus niveles, en Chile se generalizó la mercantilización del acceso a la educación superior y avanzó más la segmentación entre instituciones públicas y privadas. Es probable que esto explique la mayor desigualdad de oportunidades educativas en Chile y, por consiguiente, el bajo efecto ecualizador de la escolaridad. Es necesario profundizar en estas hipótesis con mayor evidencia.

En cualquier caso, la conclusión principal de este trabajo es que cualquier interpretación simplista que vea en la escolaridad una avenida libre para la movilidad social y la equidad de oportunidades en $A L$ se enfrentará a una realidad más compleja, en la que la escolaridad es un claro mediador, pero no siempre un ecualizador y mucho menos un atenuante de la asociación enter orígenes y destinos sociales.

\section{NOTAS}

1. En México, para los orígenes sólo es posible identificar a los trabajadores asalariados que ejercen supervisión, no a cuántos supervisa, pero junto con la información del grupo ocupacional del CIUO es posible reconstruir su posición de clase.

\section{ReferenCias BibLiogRáficas}

Alcoba, M. 2014. La dimensión social del logro individual. Desigualdad de oportunidades educativas y laborales en Argentina. México D.F: Flacso.

Balán, J., H. Browning y E. Jelin. 1977. El hombre en una sociedad en desarrollo. Movilidad geográfica y social en Monterrey. México D.F.: Fondo de Cultura Económica.

Bellei, C. (Coord.) 2013. Situación Educativa de América Latina y el Caribe: Hacia la educación de calidad para to-
En varios países de industrialización temprana se ha constatado una creciente fluidez en la estructura de clases impulsada por la igualación de oportunidades educacionales (ecualización) y por la atenuación del peso del origen en el destino de clase en la población con estudios superiores, que tendió a incrementarse por un efecto composicional de cohortes más jóvenes con mayor nivel de escolaridad (Hout 1988; Vallet 2004; Breen y Jonsson 2005; Breen et. al. 2009). En contraste, en los tres países de AL aquí analizados la escolaridad no parecería tener ese papel como medio de atenuación de la desigualdad de oportunidades entre las clases sociales, al menos entre los hombres. Esta pauta abre una interesante línea de investigación sobre qué rasgos o atributos contribuyen a mantener la desigualdad de oportunidades entre quienes logran alta escolaridad: algunos de ellos pueden estar vinculados al capital social diferencial, al prestigio de las instituciones educativas a las que acuden las personas de distintas clases sociales, a las formas de expresión y vestimenta, incluso al origen étnico, porque la discriminación hacia la población con ascendencia en los pueblos originarios implica fuertes barreras a la movilidad social ascendente en AL.

Como lo señala un estudio reciente para el caso europeo, "apuntar sólo al sistema educativo como una solución al problema de la desigualdad de oportunidades es imponerle una carga indebida. Más bien, se necesita toda una serie de políticas económicas y sociales (y de infraestructura) que tengan como meta reducir las desigualdades de condición entre las clases sociales" (Goldthorpe 2016). Las experiencias de los países que lograron una apertura de su estructura de clases han dejado huellas de que esto sólo es posible compatibilizando reformas educativas que apunten a la expansión y la democratización de la escolaridad con políticas económicas y sociales que reduzcan las desigualdades en condiciones de vida entre las clases populares y las clases medias y superiores.

2. Agrupamos los cinco niveles de escolaridad originales en tres niveles, debido a las restricciones en el tamaño de la muestra.

dos al 2015. Santiago: Oficina Regional de Educación para América Latina y el Caribe/UNESCO. Disponible en: http://www.unesco.org/new/fileadmin/MULTIMEDIA/FIELD/Santiago/images/SITIED-espanol.pdf

Benza, G. 2012. "Estructura de clases y movilidad intergeneracional en Buenos Aires: ¿el fin de una sociedad de 'amplias clases medias'?". México: Centro de Estudios Sociológicos de El Colegio de México. Tesis de doctorado. 
Blau, P. y O. D. Duncan. 1967. The American Occupational Structure. New York: Wiley.

Breen, R. (Ed.) 2004. Social Mobility in Europe. Nueva York: Oxford University Press. https://doi. org/10.1093/0199258457.001.0001

Breen, R. y J. Jonsson. 2005. "Inequality of Opportunity in Comparative Perspective: Recent Research on Educational Attainment and Social Mobility". Annual Review of Sociology 31: 223-243. https://doi.org/10.1146/ annurev.soc.31.041304.122232

Breen, R., R. Luijkx, W. Müller y R. Pollak. 2009. "Non-persistent inequality in educational attainment: Evidence from eight european countries". American Journal of Sociology 114 (5): 1475-1521.

Breen, R., K. B. Karlson y A. Holm. 2013. "Total, direct, and indirect effects in logit and probit models". Sociological Methods \& Research 42 (2): 164-191. https://doi. org/10.1177/0049124113494572

Cabrera, F. J. 2016. "La influencia del capital socioeconómico y cultural en el acceso a las instituciones de educación superior en Chile". Estudios Sociológicos 34 (100): $107-$ 143. http://dx.doi.org/10.24201/es.2016v34n100.1395

Carabaña, J. 2004. "Educación y movilidad social". En El Estado de Bienestar, editado por V. Navarro. Madrid: Tecnos-Pompeu Fabra.

Dalle, P. 2018. "Climbing up a Steeper Staircase: Intergenerational Social Mobility across Birth Cohorts in Argentina (20032010)". Research in Social Stratification and Mobility 54: 21-35. https://doi.org/10.1016/j.rssm.2017.12.002

Dalle, P. 2015. "Movilidad social intergeneracional en Argentina: oportunidades sin apertura de la estructura de clases". Revista de Ciencias Sociales 28 (37): 139-165.

Erikson, R. y J. Goldthorpe. 1992. The Constant Flux. A Study of Class Mobility in Industrial Societies. Oxford: Clarendon Press.

Featherman, D. L. y R. M. Hauser.1978. Opportunity and Change. New York: Academic Press.

Germani, G. 1963. "La movilidad social en Argentina". en Movilidad social en la sociedad industrial, editado por S. Lipset y R. Bendix. Buenos Aires: EUDEBA.

Goldthorpe, J. H. 2016. "Social class mobility in modern Britain: changing structure, constant process". Journal of the British Academy 4: 89-111. https://doi.org/10.5871/ jba/004.089

Hout, M. 1988. "More universalism, less structural mobility: the American occupational structure in the 1980s". American Journal of Sociology 93 (6): 1358-1400.

Jorrat, J. R. 2000. Estratificación social y movilidad. Un estudio sobre el Área Metropolitana de Buenos Aires. Tucumán: Editorial de la Universidad Nacional de Tucumán.

Jorrat, R. 2016. "Clase, nivel de educación y cohortes de nacimiento. Evaluación según modelos de análisis de categórico de tres y cuatro vías". En De tal padre... ¿tal hijo? Estudio sobre Movilidad Social en Argentina. Buenos Aires: Dunken.

Londoño, J. 1996. Pobreza, desigualdad y formación del capital humano en América Latina, 1950-2025.
Washington: Banco Internacional de Reconstrucción y Fomento y Banco Mundial.

López Calva, L.F. y N. Lustig (eds.) 2010. Declining Inequality in Latin America: A Decade of Progress? Washington, DC: Brookings Institution y United Nations Development Programme.

Mare, R. D. 1980. "Social Background and School Continuation Decisions". Journal of the American Statistical Association 75: 295-305. https://doi.org/10.1080/016214 59.1980.10477466

Solís, P. 2007. Inequidad y movilidad social en Monterrey. México D.F: Centro de Estudios Sociológicos.

Solís, P. e I. Puga. 2011. "Efectos del nivel socioecómico de la zona de residencia sobre el proceso de estratificación social en Monterrey". Estudios Demográficos y Urbanos 26 (2): 233-265.

Solís, P. y M. Boado (coord.). 2016. Y sin embargo se mueve...: estratificación social y movilidad intergeneracional de clase en América Latina. México D.F: El Colegio de México y Centro de Estudios Espinosa Yglesias.

Tiramonti, G. 2003. "Estado, educación y sociedad civil: una relación cambiante". En Educación Media Para Todos. Los desafíos de la democratización en el acceso, compilado por E. Tenti Fanfani. Buenos Aires: UNESCO-IIPE.

Torche, F. 2005. "Unequal but Fluid: Social Mobility in Chile in Comparative Perspective". American Sociological Review 70 (3): 422-450.

Torche, F y C. Costa-Ribeiro. 2010. "Pathways of Change in Social Mobility: Industrialization, Education and Growing Fluidity in Brazil". Research in Social Stratification and Mobility 28 (3): 291-307. https://doi.org/10.1016/j. rssm.2010.03.005

Torche, F. 2011. "Is a College Degree Still the Great Equalizer? Intergenerational Mobility across Levels of Schooling in the United States". American Journal of Sociology 117: 763-807. https://doi.org/10.1086/661904

Valenzuela, J. P., C. Bellei y D. De Los Ríos (2014). "Socioeconomic school segregation in a market-oriented educational system. The case of Chile". Journal of Education Policy 29 (2): 217-241. https://doi.org/10.1080/0268093 9.2013 .806995

Vallet L. A. 2004. "Change in intergenerational class mobility in France from the 1970s to the 1990s and its explanation: an analysis following the CASMIN approach". En Social Mobility in Europe, editado por R. Breen. Nueva York: Oxford University Press. https://doi. org/10.1093/0199258457.003.0005

Villalobos, C. y M. Quaresma. 2015. "El Sistema escolar chileno: características y consecuencias de un modelo orientado al mercado". Convergencia Revista de Ciencias Sociales 22 (69): 63-84.

Xie, Y. 1992. "The log-multiplicative layer effect model for comparing mobility tables". American Sociological Review 57: 380-395. https://doi.org/10.2307/2096242

Zenteno, R. y P. Solís. 2006. "Continuidades y discontinuidades de la movilidad ocupacional en México". Estudios Demográficos y Urbanos 21 (3): 515-546. 
PATRICIO SOLÍS es doctor en Sociología por la Universidad de Texas en Austin. Actualmente dirige la Revista Estudios Sociológicos de El Colegio de México. Entre sus publicaciones más recientes está el libro Y sin embargo se mueve... Estratificación social y movilidad intergeneracional de clase en América Latina, coordinado junto con Marcelo Boado y publicado en 2016 por El Colegio de México y el Centro de Estudios Espinosa Yglesias.

PABLO DALLE es doctor en Ciencias Sociales por la Universidad de Buenos Aires. Investigador del CONICET en el Instituto de Investigaciones Gino Germani. Profesor de Sociología de la UBA y del Instituto de Altos Estudios Sociales (UNSAM). Entre sus publicaciones más recientes está el libro Movilidad social desde las clases populares. Un estudio sociológico en el Área Metropolitana de Buenos Aires 1960-2013, publicado en 2016 por IIGG/CLACSO y CICCUS. 